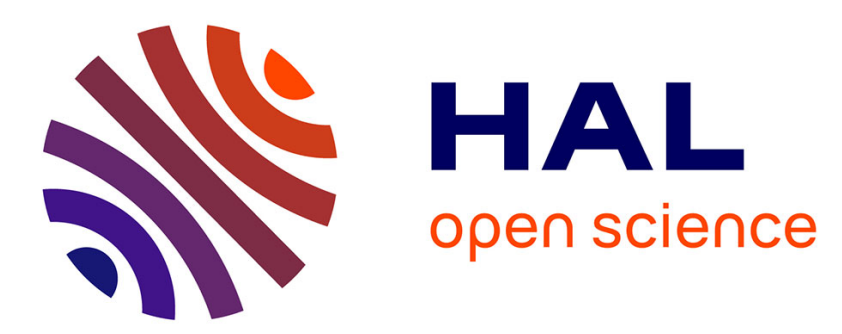

\title{
ERBIN: a basolateral PDZ protein that interacts with the mammalian ERBB2/HER2 receptor
}

Jean-Paul Borg, Sylvie Marchetto, André Le Bivic, Vincent Ollendorff, Fanny Jaulin-Bastard, Hiroko Saito, Emmanuel Fournier, Jose Adelaide, Ben

Margolis, Daniel Birnbaum

\section{To cite this version:}

Jean-Paul Borg, Sylvie Marchetto, André Le Bivic, Vincent Ollendorff, Fanny Jaulin-Bastard, et al. ERBIN: a basolateral PDZ protein that interacts with the mammalian ERBB2/HER2 receptor. Nature Cell Biology, 2000, 2 (7), pp.407-414. 10.1038/35017038 . hal-02695847

\section{HAL Id: hal-02695847 https://hal.inrae.fr/hal-02695847}

Submitted on 1 Jun 2020

HAL is a multi-disciplinary open access archive for the deposit and dissemination of scientific research documents, whether they are published or not. The documents may come from teaching and research institutions in France or abroad, or from public or private research centers.
L'archive ouverte pluridisciplinaire HAL, est destinée au dépôt et à la diffusion de documents scientifiques de niveau recherche, publiés ou non, émanant des établissements d'enseignement et de recherche français ou étrangers, des laboratoires publics ou privés. 


\title{
ERBIN: a basolateral PDZ protein that interacts with the mammalian ERBB2/HER2 receptor
}

\author{
Jean-Paul Borg* $\dagger$, Sylvie Marchetto*, André Le Bivicł, Vincent Ollendorff§̧, Fanny Jaulin-Bastard*, Hiroko \\ Saito*, Emmanuel Fournier*ף, José Adélaïde§, Ben Margolis\# and Daniel Birnbaum* $\S$
}

${ }^{*}$ U119 INSERM, Molecular Oncology, 27 boulevard Leï Roure, 13009 Marseille, France \#IBDM Faculté des Sciences de Luminy, case 907, 13288 Marseille cedex 09, France §Institut Paoli-Calmettes, 27 boulevard Leï Roure, 13009 Marseille, France

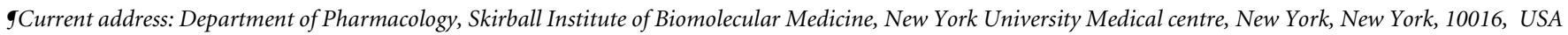
\#Howard Hughes Medical Institute, 4570 MSRBII, Box 0650, 1150 W. Medical centre Drive, Ann Arbor, Michigan, 48109-0650, USA te-mail: borg@marseille.inserm.fr

\begin{abstract}
The ERBB receptors have a crucial role in morphogenesis and oncogenesis. We have identified a new PDZ protein we named ERBIN (ERBB2 interacting protein) that acts as an adaptor for the receptor ERBB2/HER2 in epithelia. ERBIN contains 16 leucine-rich repeats (LRRs) in its amino terminus and a PDZ (PSD-95/DLG/ZO-1) domain at its carboxy terminus, and belongs to a new PDZ protein family. The PDZ domain directly and specifically interacts with ERBB2/ HER2. ERBIN and ERBB2/HER2 colocalize to the lateral membrane of human intestinal epithelial cells. The ERBINbinding site in ERBB2/HER2 has a critical role in restricting this receptor to the basolateral membrane of epithelial cells, as mutation of the ERBIN-binding site leads to the mislocalization of the receptor in these cells. We suggest that ERBIN acts in the localization and signalling of ERBB2/HER2 in epithelia.
\end{abstract}

$\mathrm{P}$

rotein-protein interactions organize the network of proteins that coordinates the signalling and trafficking of receptors. Activation of receptors endowed with tyrosine kinase activity (RTKs) leads to the tyrosine phosphorylation of the receptor and subsequent recruitment of cytoplasmic targets through Src homology two (SH2) and phosphotyrosine-binding (PTB) domains ${ }^{1,2}$. In Caenorhabditis elegans, the receptor LET-23 activates the Ras pathway in a very similar manner to its mammalian homologues, the ERBB/HER receptors, and promotes vulval development. In identifying genes encoding proteins of the Ras pathway, including LET60, SEM-5 and LIN-45, recent genetic analyses in C. elegans have shed light on new mechanisms important for RTK regulation ${ }^{3}$. For example, SUR-8/SOC2, a LRR-containing protein, participates in RTK signalling by positively regulating the Ras pathway ${ }^{4}$. The lin10, lin-2 and lin-7 genes encode three PDZ proteins that form a heterotrimeric complex important for the basolateral localization of LET-23 in the worm vulval precursor cell (VPC) ${ }^{5-8}$. Mutations within the lin-10, lin-2 and lin-7 genes produce a vulvaless phenotype, analogue to that produced by defaults in LET-23 signalling, by mislocalizing LET-23 in the VPC. In neurons, lin-10 also participates to the targeting of GLR-1, a glutamate receptor localized at the postsynaptic elements of synapses 9

The PDZ domain found in LIN-7 binds to the cytoplasmic tail of LET-23 (refs 6, 7). The binding specificities of PDZ domains are dictated by a $\mathrm{S} / \mathrm{TxV} / \mathrm{I} / \mathrm{L}$ motif (class I PDZ), in which $\mathrm{S}$ is serine, $\mathrm{T}$ is threonine, $\mathrm{x}$ is any amino acid, $\mathrm{V}$ is valine, $\mathrm{I}$ is isoleucine, and $\mathrm{L}$ is leucine, or the $\Psi \times \Psi$ tripeptide motif (class II PDZ), in which $\Psi$ is a hydrophobic residue, which is found at the $\mathrm{C}$ terminus ${ }^{10,11}$. A third class of PDZ domain (class III PDZ) is represented by the nitric oxide synthase (NOS) PDZ domain, which interacts with DxV motifs ( $\mathrm{D}$ is aspartic acid) and heterodimerizes with PSD-95 and syntrophin PDZ domains ${ }^{12-15}$. The LIN-7 PDZ domain falls within the class I PDZ domains and binds to the carboxy-terminal TCL (Thr-Cys-Leu) motif found in LET-23 (ref. 7). The LIN-7-LIN-2LIN-10 complex is conserved throughout evolution, but targets receptors other than ERBB/HER ${ }^{16,17}$. Mammalian CASK/LIN-2 interacts with syndecans and neurexins, which are cell-surface proteins ${ }^{18-20}$, whereas LIN-7/MALS/VELI proteins bind to GBT-1 and glutamate receptors in epithelia and neurons ${ }^{21-23}$. X11 proteins, the mammalian homologues of LIN-10, are partners for $\beta$-amyloid precursor protein ( $\beta$-APP) in the brain ${ }^{24}$.

Four LET-23 homologue receptors have been described in mammals: the epidermal growth factor receptor (EGFR), ERBB2/ HER2, ERBB3/HER3 and ERBB4/HER4. These form homo- and heterodimeric complexes with a wide range of signalling properties. ERBB2 is an orphan receptor activated by heterodimerization with other EGFR family members that interact with epidermal growth factor (EGF), EGF-like ligands and neuregulins. In epithelia, basolateral ERBB/HER receptors bind ligands produced by the surrounding stromal cells, and ERBB2 is thought to act as an amplifier of signalling for other family members. Overexpression of ERBB2 is frequently found in breast, ovary, lung and other epithelial cancers, and correlates with a more aggressive phenotype and a poor prognosis ${ }^{25}$. Numerous laboratories have unravelled the downstream events that follow ERBB2 activation and have analysed the role of cytoplasmic targets, which include the Src homology and collagen protein (SHC) and GRB2, in the oncogenic effects of the receptor. For example, the PTB domain of SHC binds to two $\mathrm{NPx}(\mathrm{p}) \mathrm{Y}$ motifs found in ERBB2, leading to the tyrosine phosphorylation of SHC, formation of the SHC-GRB2-SOS complex and activation of the Ras pathway ${ }^{26}$. Like LET-23 and EGFR, ERBB2 is located at the basolateral face of epithelia ${ }^{27}$. Trans-acting elements involved in ERBB2 targeting to such locations are currently unknown.

To identify proteins interacting with ERBB2, we screened a mouse kidney cDNA library using the yeast two-hybrid procedure with the nine $\mathrm{C}$-terminal residues of ERBB2 as a bait. We isolated a novel gene that encodes a protein with 16 LRRs and a single PDZ domain in its $\mathrm{C}$ terminus, which we named ERBIN. ERBIN belongs to a new family of PDZ proteins we named LAP (for LRR and PDZ), which present a conserved structure throughout evolution. The ERBIN PDZ domain interacts directly with the C-terminal amino acids of ERBB2 but not with those of other related RTKs. Conversely, other PDZ domains have no detectable affinity for ERBB2. ERBIN has a relative molecular mass $\left(M_{\mathrm{r}}\right)$ of $180,000(180 \mathrm{~K})$ and is constitutively associated with ERBB2 in living cells. Furthermore, 


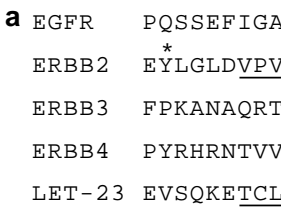

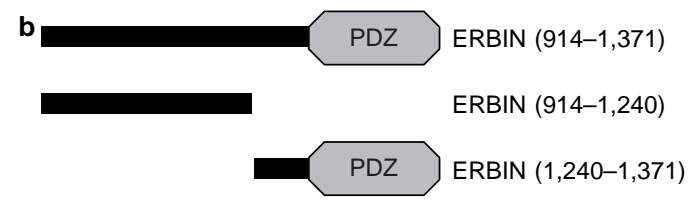

d

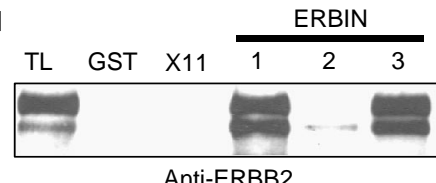

Anti-ERBB2

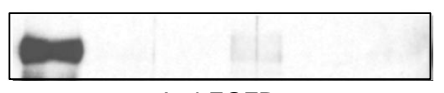

Anti-EGFR
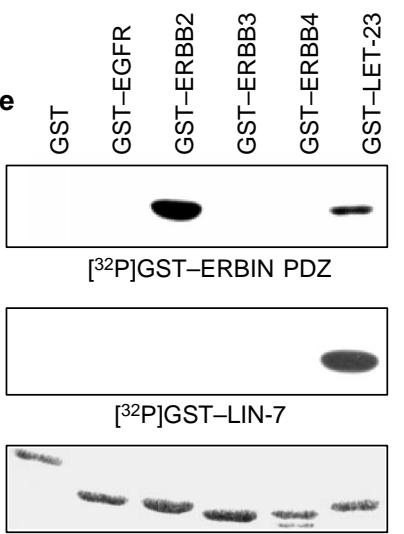

Red Ponceau

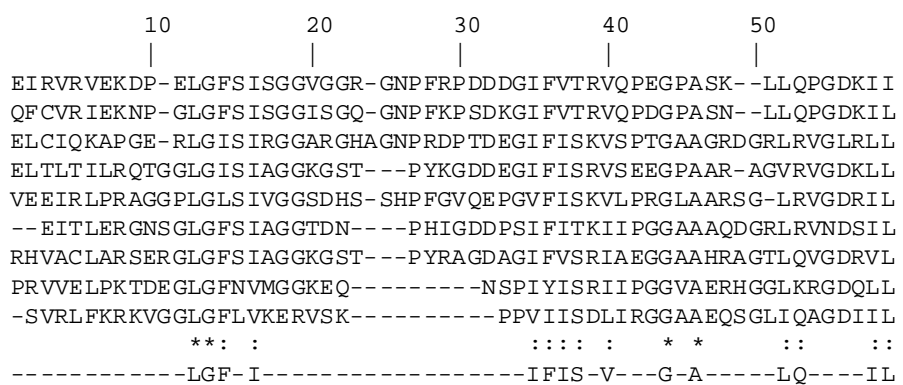

60
QANGYSFINIE HGQAVSLLKTF QNTVEL IIVREV QANGY SF I NIE HGQ AV SLL KTF QNTVEL I IVREV

ERB IN

DENSIN

hSCRI BBLE. 4 EVNOQ SLL GLT HGE AVOLL RSVGDT LTV LVCDGF EVNGVALQ GAE HHE AVEAL RGA GTA VQMRVWRER $\begin{array}{ll}\text { hSCRI BBLE.3 } & \text { AVNGQDVRDAT HQE AV SAL LRP CLE LSL LVRRDP } \\ \text { PSD 95.2 } & \text { FVNEVDVREVT HSAAVEAL KEA GS I VRL YVMR-- } \\ \text { hSCRI BBLE.2 } & \text { SINGVDVT EARHDHAVSLL TAA SPT IAL LLEREA }\end{array}$ $\begin{array}{ll}\text { hSCRI BBLE.3 } & \text { AVNGQDVRDAT HQE AV SAL LRP CLE LSL LVRRDP } \\ \text { PSD 95.2 } & \text { FVNEVDVREVT HSAAVEAL KEA GS I VRL YVMR-- } \\ \text { hSCRI BBLE.2 } & \text { SINGVDVT EARHDHAVSLL TAA SPT IAL LLEREA }\end{array}$ hSCRIBBLE.2 SINGVDVTEARHDHAVSLL TAASPT IAL LLEREA LIN-7 SVNGVSVEGEH HEKAVELLKAAKDSVKLVVRYTP NOS AVNDRPLVDLS YDS ALEVLRGI ASE THVVLI LRG

Consensus g

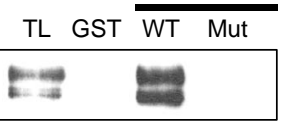

Anti-ERBB2
Figure 1 The cloning of erbin, a gene encoding a PDZ domain protein that interacts with the receptor ERBB2. a, Sequences of the last nine C-terminal amino acids found in EGFR and related receptors. PDZ-domain-binding sites in ERBB2 and LET23 are underlined. In ERBB2, a tyrosine present in a SHC PTB binding site is marked by an asterisk. b. Schematic representation of partial ERBIN isolated by the two-hybrid system. The clone pulled out from the kidney library with GAL4 BD-ERBB2 contains residues 914 to 1,371 of mouse ERBIN and is called ERBIN (914-1,371). GST fusion proteins were made using ERBIN (914-1,371), ERBIN $(914-1,240)$ and ERBIN $(1,240$ $1,371)$ peptide sequences. GST-ERBIN $(1,240-1,371)$ will be referred as GST-ERBIN PDZ domain. c, ERBIN $(914-1,371)$ and ERBIN $(1,240-1,371)$ fused to GAL4 AD interact with ERBB2 but not ERBB4 peptide. Mutation of the $\mathrm{C}$-terminal valine to alanine in ERBB2 (ERBB2. VA) abrogates the interaction. Yeast strain Y190 co-transformed with the bait and the prey vectors were plated on -Trp-Leu-His medium containing $10 \mathrm{mM}$ 3AT. (+) means growth on the selective medium (-His) and positive-galactosidase activity ( $\beta$ gal). d, Specific interaction of ERBIN PDZ domain with ERBB2 but not EGFR. HER1/2 and EGFR expressed in COS cells were precipitated by GST fusion proteins coupled to agarose beads and revealed with antiERBB2 and anti-EGFR antibodies after western blot. One- tenth of the lysate was run on gel as total lysate (TL). GST alone (GST) and GST-X11 $\alpha$ PDZ domain (X11) were used as controls. The GST-ERBIN used are: GST-ERBIN (914$1,371)$ in lane 1; GST-ERBIN $(914-1,240)$ in lane 2; and GST-ERBIN PDZ domain in lane 3. e, Direct interaction between ERBB2 peptide and ERBIN PDZ domain. The last nine amino acids of EGFR-related receptors (see a) were fused to the GST protein, western blotted and probed with soluble ${ }^{32}$ P-labelled GST-ERBIN PDZ domain or GST-LIN-7 fusion proteins. Bound proteins were revealed by autoradiography. Red Ponceau staining showed that similar amounts of GST proteins were loaded. Note that GST alone has a slower migration than GST fused to peptides because we used GSTag (GST fused to 45 irrelevant amino acids) as control. f, Sequence alignment of ERBIN, DENSIN-180, human SCRIBBLE (PDZ.1 to PDZ.4), PSD-95 (PDZ.2), LIN-7 and NOS PDZ domains. Asterisks represent conserved residues in the PDZ domain. An arrowhead points to a conserved histidine found in the $\alpha B$ helix of class I PDZ domains but not in NOS and class II PDZ domains (data not shown). g, Mutation of His-Gly to Tyr-Asp as in NOS (GST-ERBIN PDZ mut) was engineered and a pull-down was carried out on HER1/2-expressing lysates with GST, GST-ERBIN PDZ wild type (WT) and mutant (Mut). Mutation in the ERBIN PDZ domain abrogates the interaction with HER1/2 revealed by anti-ERBB2 antibody. both proteins co-localize to the basolateral membrane in epithelial cells. As with LET-23 in the VPC, mutation of the PDZ-domainbinding site in the receptor $\mathrm{C}$ terminus leads to mislocalization of ERBB2 in epithelial cells. Our results provide evidence for the existence of cellular machinery that localizes ERBB2 to the basolateral domain in epithelia, a location that is important for its activation and biological functions.

\section{Results}

ERBIN, a new partner for the receptor ERBB2. Analysis of the Cterminal peptide sequence of the ERBB receptors revealed that, like LET-23, ERBB2 contains a binding site for a PDZ domain that is conserved in humans, mice, quail and dogs (Fig. 1a). We screened a mouse kidney cDNA library using the two-hybrid system with the last nine amino acids of ERBB2 fused to the Gal4-binding domain 
a MTtK RSLF VRLV PCRC LRGE EE TVTTLDY SHCS LEQV PKEI F TFEK TLEEL YLDA NOIE ELPK OLFN CO SLH KLSL PDND LTTI PASI ANLI NLREL DVSK NGIQ EFPE NIKNC KVLT IVEA SVNP ISKL PDGF SQLL NL TQLY LNDA FLEFL PANF GRLT KLQI LEI RENQ LKML PKTM NRLT QLE RLDL GSNEF TEVP EVLE QLS GLK EFWM DANR LTF I PGF I GSLK QLTY LDVS KNNI EMVE EGIS TC ENLQ DLLL SSNS LQQL PETI GSLK NITTL KIDE NQLM YLPD S IGGL ISVEE LDCS FNEV EALP SSIG QLT NL RTFA ADHN YLQQ LPPE IGSW KNITVL FLHS NKLE TLPE EMGD MQ KLK VINL SDN RLKN LPFS FTKL $Q$ QLTAM WLSD NQSKP LIPL OKET DSET QKM VLTN YMFP QQPRTE DVMF ISDN ESFN PSLW EEQR KQRA QVAF ECDE DKDE REAP PREG NLKR YP TP YPDE LKNM VKTV QTIV HR LKDE ETNE DSGR DLKP HEDQ QDIN KDVG VKTS ESTT TVKS KV DERE KYMG NSVQ KISE PEAE ISPG SLPV TANM KASE NLKH IV NHDD VFEE SEEL SSDE EMKM AEMR PPLI ETSI NQPK VVAL SN NKKD DTKE TDSL SDEV THNS NQNN SNCS SPSR MSDS VSLN TD SSQD TSLC SPVK QTHI DINS KIRQ EDEN FNSL LQNG DILN SS TEEK FKAH DKKD FNLP EYDL NVEE RLVL IEKS VDST ATAD DT HKLD HINM NLNK LITN DTFQ PEIMERSK TQDI VLGT SFLS IN SKEE TEHL ENGN KYPN LESV NKVN GHSE ETSQ SPNR TEPH DS DCSV DLGI SKST EDLS PQKS GPVG SVVK SHSI TNME IGGL KI YDIL SDNG PQQP STTV KITS AVDG KNIV RSKS ATLL YDQP LQ VFTG SSSS SDLI SGTK AIFK FDSN HNPE EPNI IRGP TSGP OS APQIY GPPQ YNIQY SSSA AVKD TLWH SKQN PQID HASE PPQL LPRS ESTE NQSY AKHS ANMN FSNH NNVR ANTA YHLH QRLG PA RHGE MWAI SPND RLIP AVTR STIO ROSS VSST ASVN LGDP GS TRRA QIPEG DYLSY REFH SAGRTP PMMP GS QRPL SART YSID GPNA SRPQ SARP SINE IPER TMSV SDFN YSRT SPSK RPNA RV GSEH SLLD PPGK SKVP RDWR EQVL RHIE AKKL EKMP LSNG QM GQPL RPQA NYSQ IHHP PQAS VARH PSRE QLID YLML KVAH QP PYTQ PHCS PRQG HELA KQ E IRVR VEKDP ELGF SISG GVGG RG NPFR PDDD GIFV TRVQ PEGP ASKL LQPG DKII QANG YSF I NI EHGQ AVSL LKTF ONTV ELII VRE VSS b

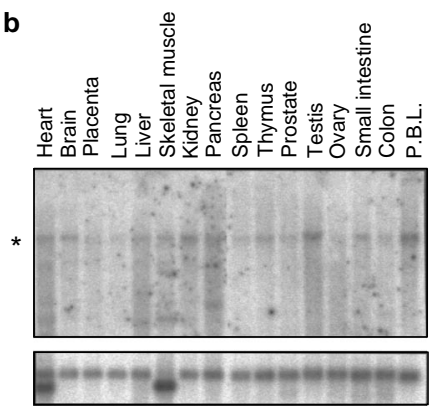

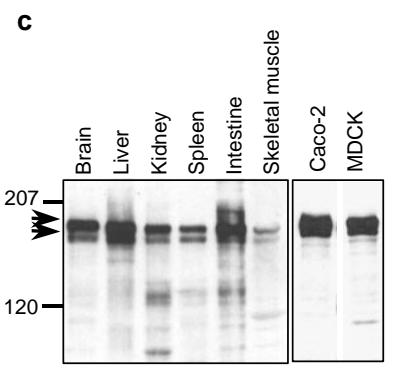

Anti-ERBIN

d

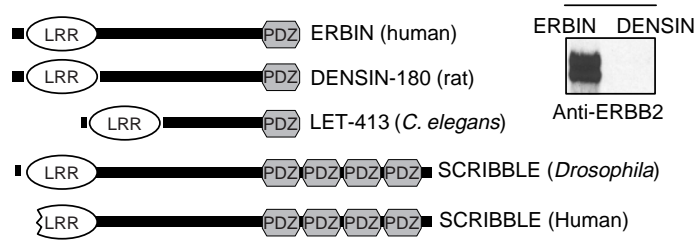

Figure 2 Characterization of ERBIN, a member of a new PDZ family. a, The protein sequence of human ERBIN. The 16 canonical LRR motifs are alternatively shown in red and green (residues 23-391) and a LRR-like domain is underlined (392429). The PDZ domain is in italics (residues $1,280-1,368$ ). Putative binding sites for $\mathrm{SH} 3$ and WW domains are underlined. $\mathbf{b}$, Northern blot analysis was carried out using Multiple Tissues Northern (Clontech). A 5' human probe was used to detect a 7.2-kb transcript in most tissues (asterisk in upper panel). The presence of equivalent amounts of poly(A)+ mRNA was verified with a probe specific for actin (lower panel). c, Total lysates of different mouse tissues and cell lines were run on SDS-PAGE, transferred to nitrocellulose and blotted with purified anti-ERBIN antibody. ERBIN is a $180 \mathrm{~K}$ protein found in most tissues and cells tested (arrows). $\mathbf{d}$, ERBIN belongs to a family of proteins containing 16 LRRs and one or four PDZ domains (left). Human SCRIBBLE is encoded by a partial CDNA clone named KIAA0147 (ref. 29). HER1/2 expressed in COS cells was precipitated by GST-ERBIN PDZ domain, but not by that of DENSIN-180 (right).
(Fig. 1a). We isolated a partial cDNA clone encoding the last 457 amino acids of a new protein hereafter named ERBIN, for ERBB2interacting protein. The ERBIN $(914-1,371)$ clone bound only to ERBB2 but not to ERBB4 peptide (Fig. 1b, c). We mutated the ERBB2 C-terminal valine, a crucial residue for PDZ domain interaction $^{10,11}$, to alanine and abolished interaction with ERBIN (Fig. 1c). A PDZ domain was found in the $\mathrm{C}$ terminus of ERBIN and was sufficient to bind to ERBB2 (Fig. 1b, c). No binding was found with EPHB2, MUSK, PDGFR $\alpha$ and PDGFR $\beta$ (data not shown). The glutathione-S-transferase (GST) fusion proteins GSTERBIN $(914-1,371)$ and GST-ERBIN PDZ bound to the chimaeric receptor EGFR/ ERBB2 (HER1/2), but not to EGFR, in pull-down assays (Fig. 1d). GST-DLG, LIN-2 and X11 $\alpha$ PDZ domains did not bind to HER1/2 (Fig. 1d, and data not shown).

Direct binding of the ERBIN PDZ domain to the ERBB receptor $\mathrm{C}$ terminus was assayed by overlay assay. The radiolabelled ERBIN PDZ domain bound to a ERBB2 peptide, but not to EGFR, ERBB3 and ERBB4 peptides, and only weakly to a LET-23 peptide (Fig. 1e). Among those receptors, the LIN-7 PDZ domain bound only to LET-23. The ERBIN PDZ domain shares the highest identity with rat DENSIN-180 (ref. 28) PDZ domain (71\%) and 35 to $40 \%$ identity with class I PDZ domains found in human SCRIBBLE ${ }^{29}$, LIN-7 and PSD-95 proteins (Fig. 1f). DENSIN-180 is not the rat homologue of ERBIN as we found a partial rat ERBIN peptide sequence in databases; it is $95 \%$ identical to human and mouse ERBIN and only $70 \%$ identical to rat DENSIN-180. A change of a His-Gly motif present in the ERBIN $\alpha B$ helix to Tyr-Asp, which is present in the NOS class III PDZ domain, abrogated the interaction with ERBB2 (Fig. 1g). These results show that the ERBIN PDZ domain interacts specifically and directly with ERBB2.

ERBIN belongs to a novel PDZ domain family. Full-length cDNA encoding human ERBIN was cloned by reverse transcription and polymerase chain reaction (RT-PCR) using mRNA from Daudi, a human B-lymphocytic cell line. An open reading frame preceded by stop codons in all three frames encodes a protein of 1, 371 amino acids. According to the Pfam protein family database ${ }^{30}$, ERBIN contains 16 LRR motifs in its amino terminus (residues 23-391) and a single C-terminal PDZ domain (residues 1, 280-1, 368) (Fig. 2a). An LRR-like domain follows the 16 canonical LRR domains (residues 392-429). A large intermediary region of 863 amino acids between the LRR domains and the PDZ domain contains prolinerich stretches that may represent binding sites for $\mathrm{SH} 3$ and $\mathrm{WW}$ (Trp-Trp) domains. A specific human erbin probe detected a 7.2-kb transcript in most human and mouse tissues tested (Fig. $2 \mathrm{~b}$ and data not shown). Specific antibodies against ERBIN were prepared, and detected a $180 \mathrm{~K}$ protein found as a doublet in brain, liver, kidney, spleen, intestine and skeletal muscle as well as in Caco-2 and MDCK epithelial cell lines (Fig. 2c). Expression of full-length erbin cDNA in COS cells produced a protein of similar size to that detected with our antibody in tissues and cell extracts (data not shown). DENSIN-180, a brain-specific protein ${ }^{28}$, and LET-413, the protein encoded by the C. elegans let-413 gene (referred as F26 D11.11 gene in databases) (M. Labouesse, personal communication), show the same structure as ERBIN (Fig. 2d). SCRIBBLE, a 

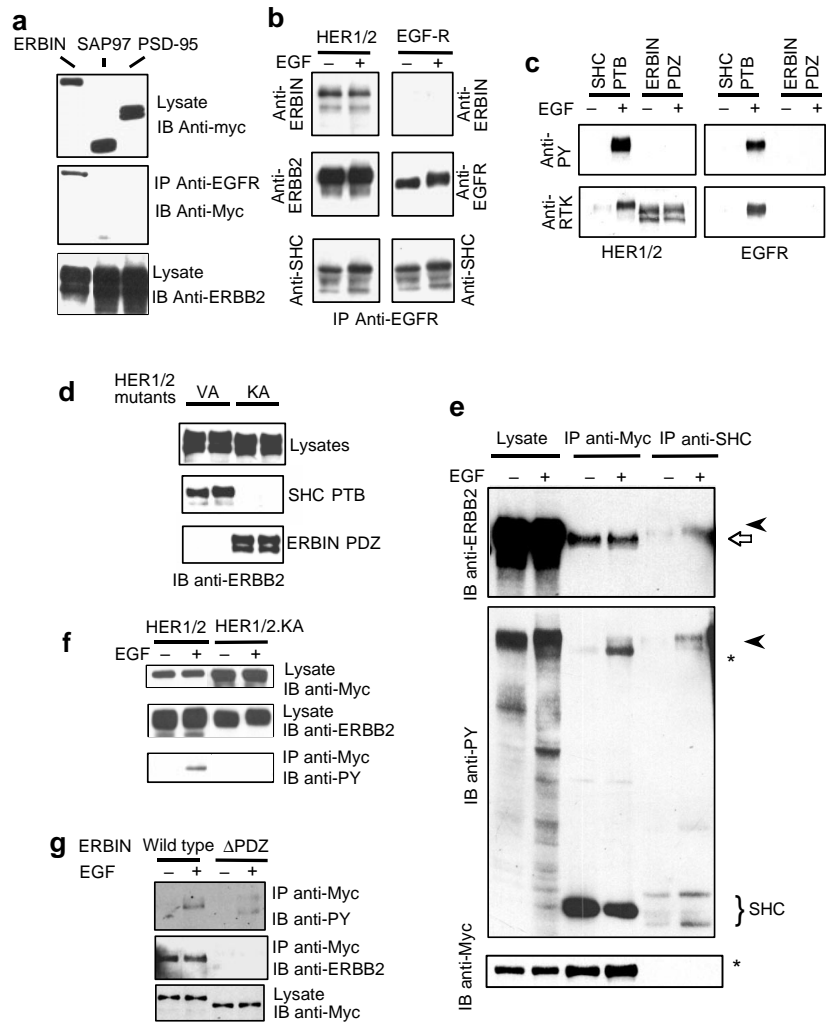

Figure 3 ERBIN interacts preferentially with the non-activated HER1/2 receptor.

a, HER1/2 was transiently co-expressed with Myc-tagged ERBIN, SAP97 and PSD-95 in COS-1 cells. HER1/2 was immunoprecipitated (IP) with anti-EGFR antibody (clone 108 ) and bound proteins were revealed by immunoblotting (IB) with anti-Myc and antiERBB2 antibodies, respectively. Only ERBIN is associated with HER1/2. b, HER1/2 and EGFR were transiently co-expressed with ERBIN in COS-1 cells. Equal amounts of ERBIN and receptors are found in the lysates (data not shown). Receptors were immunoprecipitated by anti-EGFR antibody, bound proteins were western blotted and revealed with anti-ERBIN and antireceptor antibodies. Only HER1/2 interacts with ERBIN. As a control, p52 SHC protein is increasingly co-immunoprecipitated with HER1/ 2 and EGFR after EGF stimulation. c, HER1/2 and EGFR were transiently expressed in COS-1 cells. GST pull down assays were performed using purified GST-SHC PTB or GST-ERBIN PDZ domains bound on agarose beads. Precipitated proteins were revealed by western blot analysis using anti-PY antibody (upper panels). After stripping, membranes were revealed with anti-ERBB2 and anti-EGFR antibodies, respectively (antiRTK). While only phosphorylated receptors bind to the SHC PTB domain,

unphosphorylated HER1/2 interacts with the ERBIN PDZ domain. d, HER1/2 containing a mutation of the C-terminal valine (mutant VA) or a kinase-dead HER1/2 (mutant KA) were expressed in COS-1 cells and interaction with GST fusion proteins was tested as described in c. e, Myc-tagged ERBIN was co-expressed with HER1/2 in COS cells. After lysis, anti-Myc or anti-SHC antibodies were used for immunoprecipitation. After western blotting, the membrane was successively probed with anti-ERBB2, anti-PY and anti-Myc antibodies, respectively. The white arrow shows unphosphorylated HER1/2 receptor co-immunoprecipitated with ERBIN in the top panel. The arrowheads point to phosphorylated HER1/2 interacting with SHC proteins in the top and middle panels. Note the slower migration of phosphorylated HER1/2 (arrowhead) compared to the unphosphorylated HER1/2 in the upper panel. In the middle and bottom panels, an asterisk indicates the position of Myc-ERBIN. SHC proteins (p52 and p46 SHC) are indicated at the bottom of the gel. ERBIN is phosphorylated by HER1/2 but interacts preferentially with the unphosphorylated receptor, in contrast to SHC proteins. $\mathbf{f}$, As in e but a kinase-dead HER1/2 (HER1/2. KA) was also co-expressed with Myc-ERBIN. ERBIN is tyrosine phosphorylated when co-expressed with HER1/2 but not HER1/2. KA (bottom panel). Lysates were also run on SDS-PAGE, transferred to nitrocellulose and revealed with anti-Myc (top panel) and anti-ERBB2 (middle panel) antibodies. g, HER1/2 was co-expressed with Myc-tagged wild type ERBIN or ERBIN lacking its PDZ domain ( $\triangle P D Z$ ). Deletion of the PDZ domain inhibits interaction with HER1/2 and decreases ERBIN tyrosine phosphorylation.
Drosophila protein important for epithelial integrity ${ }^{29}$, has $16 \mathrm{~N}$-terminal LRRs $44 \%$ identical to ERBIN LRRs and $47 \%$ identical to DENSIN-180 LRRs, and four PDZ domains 35-40\% identical to ERBIN and DENSIN-180 PDZ domains. KIAA0147, a putative protein found in databases, lacks N-terminal sequences but probably represents the human SCRIBBLE homologue ${ }^{29}$. The region between the LRR and PDZ domains in this protein family is divergent, suggesting that it mediates specific protein interactions for each member. Despite high sequence identity between the PDZ domains of DENSIN-180 and ERBIN (71\%), only the ERBIN PDZ domain bound to ERBB2 in a GST pull-down assay (Fig. 2d). Structural similarity between ERBIN, DENSIN-180, SCRIBBLE and LET-413 led us to consider these proteins as members of a new PDZ family we have designated LAP, for LRR and PDZ domain proteins.

ERBIN and ERBB2 associate in living cells. In vivo interaction

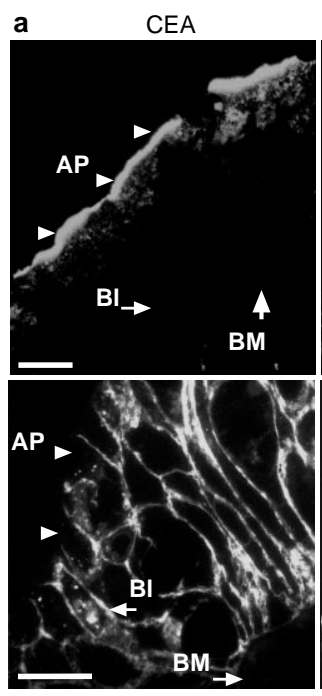

525

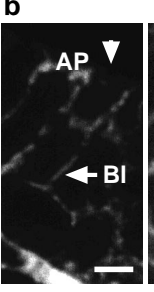

ERBB2

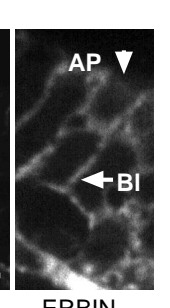

ERBIN

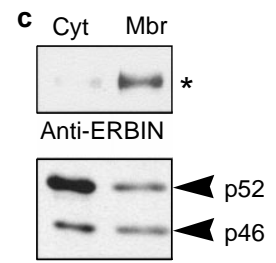

Anti-SHC
Figure 4 Basolateral localization of ERBIN and ERBB2 in human colon. a, Semi-thin frozen sections of human colon were double-stained with antibodies against ERBIN and an apical marker, CEA, or a basolateral marker, Ag525. Apical (AP) and basolateral (BI) membranes are indicated by arrowheads and arrows respectively. The location of the basement membrane (BM) is also indicated. ERBIN co-localizes with $\mathrm{Ag} 525$ on the basolateral membrane. $\mathbf{b}$, Semi-thin frozen sections of human colon were double-labelled with antibodies against ERBIN and ERBB2. Both proteins are localized on the basolateral membrane (BI) and are absent from the apical membrane (AP). Scale bars represent $5 \mu \mathrm{m}$. c, Cell fractioning was carried out on Caco-2 cells and cytosolic (Cyt) and membrane (Mbr) fractions were subjected to western blot analysis with anti-ERBIN and anti-SHC antibodies. Whereas SHC proteins are mainly cytosolic (arrowhead), ERBIN is found in the membrane fraction (asterisk). d, Proteins of Caco-2 cell lysates were immunoprecipitated with anti-ERBIN (E) or preimmune serum (not shown) or a control rabbit antibody (anti-STK-1) (C) and precipitated proteins were resolved by western blot. Anti-ERBB2 and anti-ERBIN antibodies were used to probe the membrane. Co-immunoprecipitation between ERBB2 and ERBIN was evidenced only when anti-ERBIN antibody was used for immunoprecipitation. One-tenth of the Caco-2 lysate was run as control (TL). 

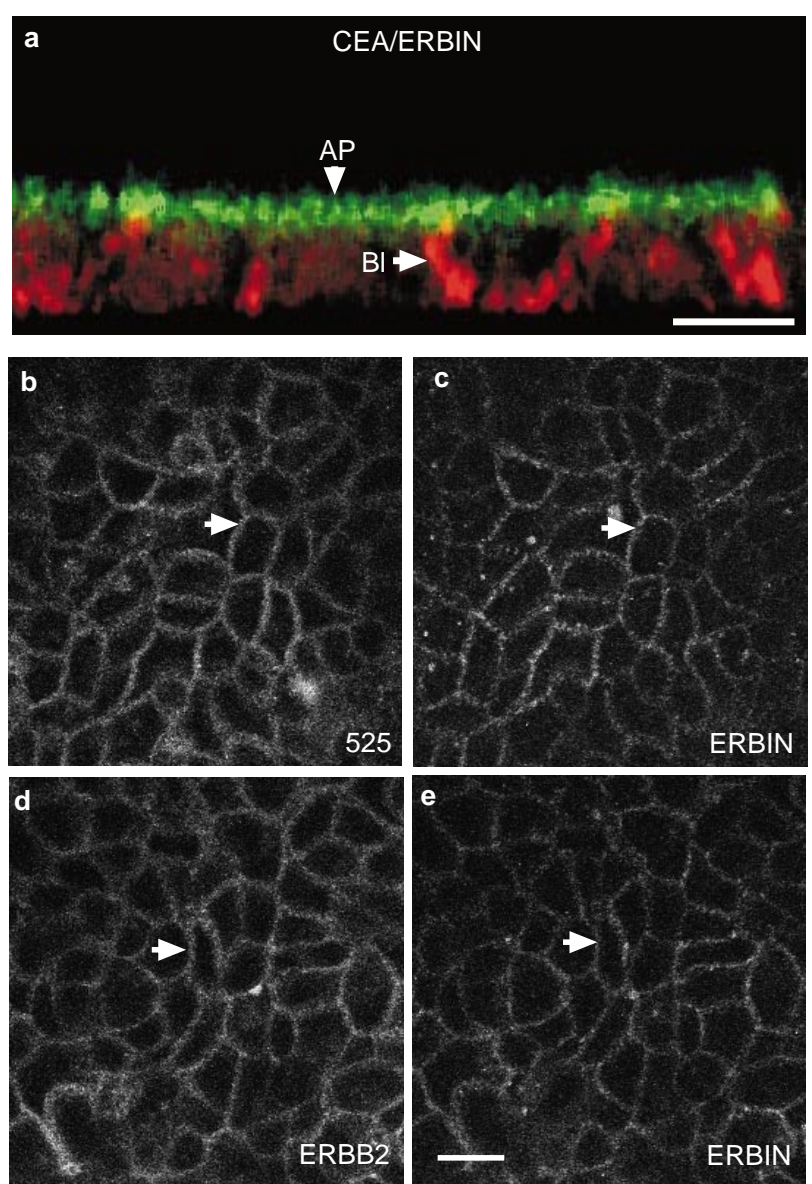

Figure 5 Basolateral localization of ERBIN and ERBB2 in Caco-2 cells. Confocal sections of Caco-2 cells double labelled for: $\mathbf{a}$, the apical marker CEA in green and ERBIN in red; $\mathbf{b}, \mathbf{c}$, for the basolateral marker Ag525 and ERBIN; d,e, for ERBB2 and ERBIN. $\mathbf{a}$ is a $Z$ section and $\mathbf{c}$-e are X-Y sections at the level of the lateral membranes. Apical (AP) and basolateral (BI) membranes are marked by arrowheads and arrows respectively. ERBIN is restricted to the basolateral domain of Caco-2 cells. Scale bars represent $10 \mu \mathrm{m}$.

between ERBIN and ERBB2 was tested by co-immunoprecipitation experiments in COS cells. A Myc-tagged ERBIN interacted only with HER1/2 whereas two other PDZ-containing proteins, SAP97 and PSD-95, did not (Fig. 3a). HER1/2, but not EGFR, co-immunoprecipitated with ERBIN regardless of EGF stimulation (Fig. 3b). In contrast, p52 SHC was increasingly associated with both receptors after activation ${ }^{26}$. Next, pull-down experiments were done with GST-SHC PTB and GST-ERBIN PDZ domains on lysates containing HER1/2 and EGFR. The SHC PTB domain interacted only with phosphorylated ERBB receptors (Fig. 3c). In contrast, when a GSTERBIN PDZ domain was used to pull down HER1/2 out of lysates, only non-phosphorylated HER $1 / 2$ was precipitated by the PDZ domain because bound receptor was recognized by anti-ERBB2 but not by anti-PY antibody (Fig. 3c). A kinase-dead (enzymatically inactive) HER1/2 receptor (HER1/2.KA) was transiently expressed in COS cells in parallel with a HER1/2. VA mutant, in which the Cterminal valine is changed to alanine. Mutation VA in HER1/2 did not affect the tyrosine phosphorylation of the receptor whereas the kinase-dead mutant was not tyrosine phosphorylated (data not shown). As expected, the HER1/2.KA mutant did not bind to the GST-SHC PTB domain (Fig. 3d). On the other hand, the ERBIN PDZ domain efficiently precipitated HER1/2. KA, but not HER1/2. VA. Taken together, these results show that the ERBIN PDZ domain interacts with non-activated HER1/2 receptor. As a tyrosine contained in a site that binds to the SHC PTB domain is found in the $\mathrm{C}$ terminus of ERBB2 five residues upstream of the binding site for the PDZ domain (Fig. 1a), phosphorylation of the tyrosine or recruitment of SHC proteins at this site after receptor activation may preclude interaction with the ERBIN PDZ domain. Phosphorylation of this tyrosine is, however, not sufficient to alter the HER1/ 2-PDZ domain interaction, as a tyrosine-phosphorylated peptide (last 15 residues of ERBB2) inhibited this interaction as efficiently as a non-phosphorylated peptide (data not shown). The PDZ domain interaction is thus probably inhibited by competition with protein modules of the signalling machinery.

We next co-expressed a Myc-tagged ERBIN with HER1/2 in COS cells to find out if the proteins behaved identically in vivo. Indeed, we found that the pool of HER1/2 associated with ERBIN was mostly not phosphorylated on tyrosine after EGF stimulation (Fig. 3e). Only a faint band, probably corresponding to a fraction of phosphorylated receptor dimerized with unphosphorylated receptors, was associated with ERBIN. In contrast, SHC proteins interacted with the phosphorylated receptor. ERBIN is a substrate for the ERBB2 kinase or a kinase activated by the receptor and no ERBIN phosphorylation was found when we expressed a kinasedead HER1/2 receptor (Fig. 3f). Deletion of the ERBIN PDZ domain inhibited the interaction with HER1/2 and decreased but did not eliminate, tyrosine phosphorylation of ERBIN (Fig. $3 \mathrm{~g}$ ). Conversely, deletion of the six last C-terminal residues in HER1/2 decreased ERBIN phosphorylation by the receptor (data not shown). As in the case of AF-6, a PDZ protein interacting with EPHB3, interaction is not an obligatory step for phosphorylation ${ }^{31}$. Together, these data show that ERBIN interacts with non-tyrosinephosphorylated HER1/2, and that ERBIN tyrosine phosphorylation is dependent on ERBB2 kinase activity.

ERBIN and ERBB2 colocalize to the basolateral side of epithelia. To determine the subcellular localization of ERBIN, we performed immunostainings on semi-thin frozen sections of human colon with anti-ERBIN antibody. ERBIN colocalized in epithelial cells with $525 \mathrm{Ag}$, a well known marker of the basolateral membrane in intestinal cells ${ }^{32}$ (Fig. 4a). No colocalization was observed with carcinoembryonic antigen (CEA), an apical marker, confirming that ERBIN was basolaterally located in human intestinal cells (Fig. 4a). Furthermore, ERBB2 was also basolateral and colocalized with ERBIN (Fig. 4b). Cell fractionation showed that ERBIN was mainly present in the membrane fraction, whereas SHC proteins were predominantly in the cytosolic fraction in epithelial cells (Fig. 4c). Endogenous ERBIN co-immunoprecipitated with ERBB2 in Caco2 cells (Fig. 4d). Only a fraction of ERBB2 was involved, however; this may be explained by the fact that our anti-ERBIN antibody is directed against the PDZ domain and competes for the interaction, or that other proteins, including $\mathrm{PDZ}$ proteins, interact with the ERBB2 C-terminal region.

To confirm the basolateral colocalization of ERBIN and ERBB2, we used Caco-2, a human colon carcinoma cell line that expresses both proteins. We performed double-immunostaining and confocal sections of permeabilized Caco- 2 cells with anti-ERBIN antibody. In double-labelled stainings, ERBIN was found at the basolateral side of Caco-2 plasma membranes in confocal $\mathrm{Z}$ section, in contrast to apical CEA (Fig. 5a), and colocalized with $525 \mathrm{Ag}$ and $\mathrm{ERBB} 2$, further suggesting that ERBIN and ERBB2 interact in vivo (Fig. 5b-e). Taken together, these results show that ERBIN and ERBB2 co-localize to the basolateral epithelia in tissues and culture cells.

Mutation of the ERBIN-binding site leads to mislocalization of HER1/2. In C. elegans, a PDZ protein complex composed of LIN-7, LIN-2 and LIN-10 localizes LET-23 at the basolateral side of the vulval precursor cells ${ }^{7}$. Mutation of the C-terminal residue in LET23 abrogates the binding to LIN-7 PDZ domain and impairs the proper localization of the receptor. Similarly, mutation of the Cterminal valine in ERBB2 abrogated the binding to ERBIN (Figs 1, 

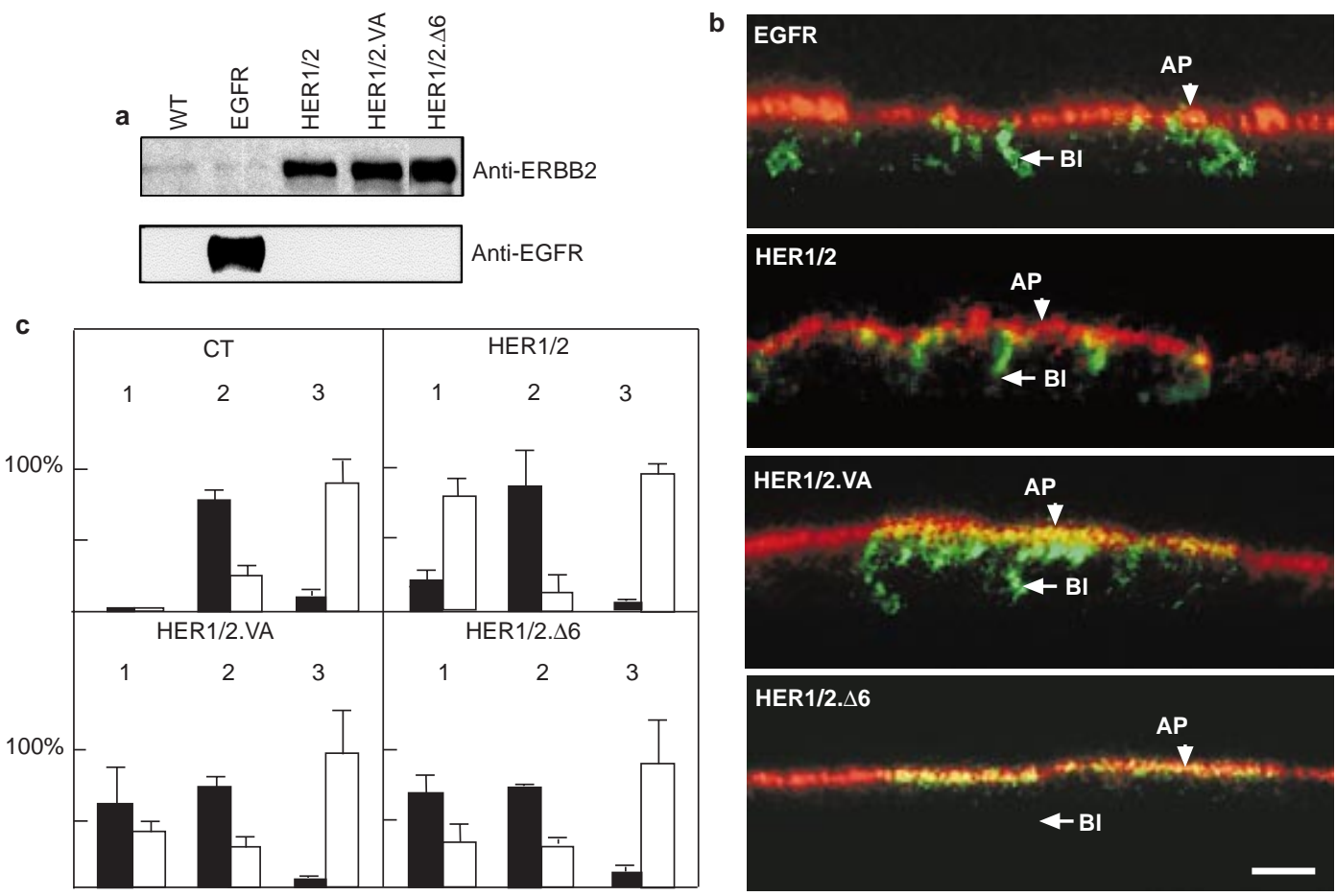

Figure 6 Basolateral localization of ERBB2 in epithelial cells relies on the presence of an intact ERBIN-binding site. MDCK cells were stably transfected with cDNAs coding for EGFR, HER1/2, HER1/2. VA and HER1/2. 46 . a, Receptors were detected in cell lysates by western blot analysis with anti-ERBB2 (upper panel) and antiEGFR (lower panel) antibodies. b. Double-labelling was done after permeabilization with LA22, a monoclonal antibody directed against the extracellular domain of the EGFR, (in green) and a polyclonal antibody against an endogenous apical marker, Gp114 (in red). Confocal Z sections were analysed and apical (AP) and basolateral (BI) membranes are indicated by arrowheads and arrows respectively. Scale bar represents $10 \mu \mathrm{m}$. Whereas Gp114 is always apical and EGFR and HER1/2 are concentrated on the basolateral membrane, HER1/2. VA and HER1/2. 6 are localized respectively in part or totally at the apical membrane. c, Surface expression of EGFR, HER1/2, HER1/2. VA and HER1/
2. $\Delta 6$ in MDCK at steady state. Cells were grown on filters and labelled overnight with $\left[{ }^{35} \mathrm{~S}\right]$ methionine. Surface-expressed receptors were biotinylated from the apical or basolateral side. After cell lysis, receptors were immunoprecipitated with anti-EGFR antibody and reprecipitated with streptavidin beads. Precipitates were analysed by SDSPAGE and revealed by fluorography. Two endogenous antigens of MDCK cells (Gp114, an apical marker, and $\mathrm{BC} 11$, a basolateral one) were immunoprecipitated from the same lysates and their distribution was determined as for EGFR (data not shown) and HER1/2 (wild type and mutants). Quantification of apical and basolateral surface expression was done by scanning densitometry and expressed as a percentage of total surface expression ( \pm s.d.). Black bars represent apical expression and empty bars basolateral expression. $n=3$ except for HER1/2, where $n=2$. CT, control cells expressing no receptor. 1, HER1/2 receptor; 2, Gp114 marker; 3, BC11 marker.
3). To test if the ERBIN-binding site in ERBB2 is important for the localization of the receptor, we produced MDCK cells stably expressing EGFR, HER1/2 and HER1/2. VA proteins. Cells expressing receptors were sorted with anti-EGF receptor monoclonal antibody (clone 108) and selected populations presenting similar amounts of receptor at the cell surface (data not shown).

MDCK cells express low levels of endogenous EGFR and ERBB2 receptors, making it possible to detect ectopic EGFR and HER1/2 (wild type and mutant) receptors with the appropriate antibody (Fig. 6a). Confocal analysis of the subcellular distribution of ectopic receptors was performed on cells at least three days after confluency. Cells were double-stained with an antibody directed against Gp114, a major apical protein in MDCK cells ${ }^{33}$, and LA22, an antibody directed against the extracellular domain of human EGFR. Z sections showed that whereas EGFR and HER1/2 were mainly localized to the basolateral membrane, HER1/2. VA was found both on apical and basolateral membranes (Fig. $6 \mathrm{~b}$ ). We also produced a mutant receptor missing the six C-terminal residues of HER1/2 (HER1/2.A6; Fig. 6a). This truncation abrogated the interaction with ERBIN in pull-down and co-immunoprecipitation experiments (data not shown) and completely delocalized HER $1 / 2$ from the basolateral to the apical membrane, where Gp114 is located (Fig. 6b). Cell-surface biotinylation was done on the apical or the basolateral membranes of the same MDCK populations and the surface expression of the receptors was determined. Whereas
HER1/2 was found mainly located to the basolateral membrane, mutation or truncation of the ERBIN-binding site led to mislocalization of the receptor (Fig. 6c). Endogenous markers such as Gp114 and $\mathrm{BC} 11$, a basolateral protein, were also immunoprecipitated and their surface polarity was expressed as a percentage of the total cellsurface expression. No change in polarity of these markers was observed, indicating that expression of mutant receptors with a different polarity had no consequence on the overall polarity of MDCK cells (Fig. 6c). Thus, removing the site of interaction with ERBIN leads to ERBB2 mislocalization in epithelial cells.

\section{Discussion}

The restricted localization of receptors in polarized cells is an important step in receiving signals and promoting the appropriate cellular responses. This is true for ERBB2, which is an orphan receptor activated by heterodimerization with other basolateral receptors such as EGFR. Basolateral targeting in epithelia appears to be controlled by several different peptide sequences within the intracellular domain of proteins, although little is known about the machinery that drives this process ${ }^{34-37}$. We have shown that ERBIN, a new PDZ protein, binds to ERBB2 in vitro and in vivo. The ERBB2-ERBIN interaction is direct, specific and occurs when ERBB2 is not phosphorylated. As both ERBIN and ERBB2 are located to the basolateral epithelia in Caco-2 cells and human 
colon, we propose that ERBB2 is localized to the basolateral membranes of the epithelium by interacting with ERBIN. Although we cannot totally exclude the possibility that other PDZ proteins may bind to ERBB2, we have demonstrated by many approaches that the ERBB2-ERBIN interaction is specific and probably occurs in vivo. This idea is reinforced by the fact that mutation of the ERBIN-binding site in the receptor causes mislocalization of ERBB2 in MDCK cells.

PDZ domain proteins have emerged as central molecules for the scaffolding of receptors and ligands in synapses and epithelia. They cause the clustering of voltage-gated ion channels and receptors, presumably to permit a more efficient response to stimuli. For example, PSD-95 is found at postsynaptic sites, where it forms a scaffold for glutamate receptors, potassium channels and neuroligins, and LIN-2/CASK targets neurexins at presynaptic sites ${ }^{11,38,39}$. In epithelia, the zonula occludens ( $\mathrm{ZO}$ ) family comprises tight junction proteins that recruit occludin and catenins, whereas SAP97/ hDLG, VELI/LIN-7 and CASK/LIN-2 are localized at the basolateral membranes of the epithelium ${ }^{23,40,41}$. In Drosophila, INAD scaffolds a protein kinase $\mathrm{C}$, calmodulin, phospholipase $\mathrm{C}$, rhodopsin and a light-sensitive $\mathrm{Ca}^{2+}$ channel in a stable transducisome machinery that is crucial for signalling and stability of photoreceptors $^{42,43}$. The molecular interactions of PDZ domain proteins are crucial for epithelial morphogenesis, as shown by the loss of epithelial integrity of $d l g$ and $d l t$ mutants in Drosophila or the inadequate vulval development of the nematode in lin-7, lin-2 and lin-10 mutants ${ }^{44-46}$. SHROOM, a PDZ protein localized to adherens junctions and the cytoskeleton, is essential for mice to develop a normal cytoskeletal polarity within the neuroepithelium ${ }^{47}$. Interestingly, LET-413 (M. Labouesse, personal communication), and SCRIBBLE $^{29}$, two epithelial LAP proteins, are required for proper assembly of adherens junctions and apical distribution of proteins in C. elegans and Drosophila, respectively.

ERBIN represents a novel type of adaptor protein that features an organization of protein modules probably involved in connecting ERBB2 to cytosolic and cytoskeleton-associated components. The LAP family we have described (Fig. 2d) probably scaffolds many other proteins, including receptors, in various polarized cells including epithelial cells and neurons. Mutations in let-413 (M. Labouesse, personal communication) and scribble ${ }^{29}$ genes have profound effects on epithelial integrity, and genetic analysis will determine the role of other lap genes in developmental processes in mammals. As ERBIN is a partner for ERBB2, our data also suggest a role for ERBIN in the signalling from the receptor. EGFR differs from the other ERBB/HER receptors in its ability to interact with and phosphorylate the product of the $c$ - $C b l$ protooncogene ${ }^{48}$, whereas only ERBB3 binds to the p85 subunit of phosphatidylinositol 3-kinase (PI3-kinase) ${ }^{49}$. We show here that ERBB2 is the only ERBB/HER member to be associated with ERBIN. Specificity of signalling in the ERBB/HER family may thus be elicited by the formation of heterodimers, bringing together different scaffolding proteins. The LRR motifs found in ERBIN share $38 \%$ identity with the LRRs of SUR-8/SOC2 proteins, which were shown to bind to Ras ${ }^{4}$. We did not detect an interaction between the LRR of ERBIN and Ras in the two-hybrid system (data not shown), but other small G proteins may constitute binding partners for ERBIN. The characterization of a new family of adaptors for ERBB receptors will probably provide important information on the control of epithelial homeostasis, and in consequence, on the pathology of carcinomas.

\section{Methods \\ Two-hybrid procedure.}

The nine last amino acids of ERBB2 were fused to the GAL4 BD subunit using pc97 vector which carries LEU2. An oligo-dT primed mouse cDNA embryonic kidney library cloned in pc86 vector, which carries Trp1 as a selection marker, was screened using the GAL4 BD-ERBB2 bait and the yeast strain Y190 following the lithium-acetate protocole. Approximately $10^{6} T R P^{+} L E U^{+}$transformants were selected on plates with supplemented minimal medium that lacked tryptophan, leucine and histidine in the primary screening and contained $10 \mathrm{mM} 3$-aminotriazole (3AT), and then tested for $\beta$-galactosidase activity by the filter method in the secondary screening. After rescue, the DNA of selected clones was retransformed in Y190 yeast containing GAL4 BD-ERBB2 or GAL4 BD fused to control peptides. A specific clone was positive for growth in histidine deficient medium and $\beta$-galactosidase activity and encodes for ERBIN (914-1, 371). Alternatively, the last 15 amino acids of ERBB2, mutated ERBB2 (mutant VA) and ERBB4 were fused to the LexA protein by using the PBTM116 vector, which carries Trp1. The ERBIN PDZ domain was fused to the GAL4 AD subunit, encoded by the pACT2 vector which carries $L E U$. Interactions were performed in the yeast strain L40.

\section{Protein procedures.}

Cells were washed twice with cold PBS and lysed in lysis buffer (50mM HEPES pH7.5, $10 \%$ glycerol, 150 $\mathrm{mM} \mathrm{NaCl}, 1 \%$ Triton X-100, $1.5 \mathrm{mM} \mathrm{MgCl} 2,1 \mathrm{mM} \mathrm{EGTA}$ ) supplemented with one mM phenylmethylsulphonylfluoride (PMSF), $10 \mu \mathrm{g} \mathrm{ml}^{-1}$ aprotinin and $10 \mu \mathrm{g} \mathrm{ml}^{-1}$ leupeptin. Sodium orthovanadate at $200 \mu \mathrm{M}$ final concentration was added to lysis buffer when cells were stimulated by EGF. After centrifugation at $16,000 \mathrm{~g}$ for $20 \mathrm{~min}$, lysate protein content was normalized using the Bio-Rad protein assay kit. For immunoprecipitation, lysates were incubated with antibodies overnight at $4{ }^{\circ} \mathrm{C}$. Protein A-agarose was added and immune complexes bound to beads were recovered after one $\mathrm{h}$, washed three times with HNTG buffer (50 mM HEPES pH7.5, $10 \%$ glycerol, $150 \mathrm{mM} \mathrm{NaCl}, 0.1 \%$ Triton X-100), boiled in $1 \times$ sample buffer, and separated by SDS-PAGE. Transfer and immunoblotting on nitrocellulose using HRP-anti-rabbit or HRP-anti-mouse antibody/chemiluminescence method were performed as described $^{24}$. For overlay assays, the membrane was incubated two $\mathrm{h}$ at room temperature with soluble GST fusion proteins labelled with protein kinase A and $\left[\gamma^{-32} \mathrm{P}\right]$ ATP diluted in TBS- $5 \%$ dried milk, one mM DTT $\left(10^{6}\right.$ c.p.m. $\left.\mathrm{ml}^{-1}\right)$. After rinsing with TBS- $0.1 \%$ Triton X-100 and TBS buffers, bound GST was revealed by autoradiography. Cell transfection, GST production and GST binding assays were performed as previously described ${ }^{24}$.

Fractionated lysates were prepared as follows: cells were lysed in hypotonic buffer $(10 \mathrm{mM}$ Tris-Cl pH 7.4, $0.2 \mathrm{mM} \mathrm{MgCl}^{2}, 5 \mathrm{mM} \mathrm{KCl}$ ) supplemented with one mM PMSF, $10 \mu \mathrm{g} \mathrm{ml}^{-1}$ aprotinin and $10 \mu \mathrm{g} \mathrm{ml}^{-1}$ leupeptin. Lysis was completed by 20 strokes in an ice-cold dounce (B piston). Sucrose was added to the homogenate to a final concentration of $0.25 \mathrm{mM}$, and EDTA to one $\mathrm{mM}$, and non-homogenized debris was removed by centrifugation at $1,000 \mathrm{~g}$ for $10 \mathrm{~min}$ at $4^{\circ} \mathrm{C}$. The supernatant was then centrifuged at $138,000 \mathrm{~g}$ for $1 \mathrm{~h}$ at $4^{\circ} \mathrm{C}$. The supernatant was collected and called the cytoplasmic fraction. The pellet was resuspended in a volume of lysis buffer (described above) equivalent to the volume of the cytoplasmic fraction. After $30 \mathrm{~min}$ on ice, insoluble debris was removed by centrifugation at $16,000 \mathrm{~g}$ for $30 \mathrm{~min}$ at $4{ }^{\circ} \mathrm{C}$. The resulting supernatant was called the membrane fraction.

\section{Cell culture.}

COS-1 and MDCK cells were grown in Dulbecco Modified Eagle Medium (DMEM) containing $100 \mathrm{U} \mathrm{ml}^{-1}$ penicillin and $100 \mu \mathrm{g} \mathrm{ml}^{-1}$ streptomycin sulphate, supplemented with $10 \%$ fetal calf serum (FCS). Caco-2 cells were maintained in DMEM medium supplemented with $20 \%$ FCS and $1 \%$ nonessential amino acids. All cell transfections were made using Fugene 6 reagent according to the manufacturer's recommendations (Boehringer).

\section{DNA constructs.}

Human erbin cDNA was cloned from Daudi cell mRNA by RACE RT-PCR using the Marathon kit according to the manufacturer's recommendations (Clontech). We also created a contig of overlapping expressed sequence tagged (EST) clones originated from various human tissues and cell lines that reconstituted the full human erbin cDNA (GenBank accession numbers 417970, 105245, 773261 and 774284). Human erbin cDNA was used as a template to create different constructs, allowing expression of GST or Myc-tagged fusion proteins. The RK5 -myc vector was used to express proteins fused to the Myc epitope ${ }^{24}$. The pGEX-Tag vector was used to produce all GST fusion proteins. Site-directed mutagenesis was performed using the Quick-Change kit (Stratagene). All constructs were sequenced by Genome Express, SA (Grenoble, France).

A rat cDNA library was used as a template to amplify a 600 bp fragment encoding the DENSIN-180 PDZ domain (residues 1, 342-1,492). GST-X11 $\alpha$ and LIN-2 PDZ domain have already been described ${ }^{16}$. EST 814570 was cloned in-frame into the pGEX-Tag vector, allowing expression of residues 196 to 315 of human Discs-large (DLG) encompassing the first PDZ domain.

\section{Antibodies.}

Anti-Myc 9 E10 (Oncogene Research Products) monoclonal antibody was used for immunoprecipitation and immunoblotting. Anti-ERBB2 and anti-EGFR rabbit polyclonal antibodies were obtained by injecting peptides in rabbits. Anti-EGFR monoclonal $(\mathrm{mAb})$ antibody $(108)$ was used for immunoprecipitation. Anti-EGFR mAb (clone LA22) from Upstate Biotechnology (UBI) was used for immunofluorescence. Anti-SHC polyclonal and $4 \mathrm{Gl} 1 \mathrm{mAb}$ (anti-PY) antibodies are from UBI. AntiSTK-1 antibody was from Santa Cruz. Goat anti-rabbit and anti-mouse IgG coupled to horseradish peroxidase were purchased from Jackson Laboratory and Dako, respectively. A rabbit anti-ERBIN polyclonal antibody was produced by injecting a soluble GST-ERBIN $(914-1,371)$ fusion protein. The anti-ERBIN antibody was subsequently affinity purified with a His-tagged ERBIN $(914-1,371)$ protein bound to nickel-agarose beads (Qiagen).

\section{Northern blot analysis.}

Multiple-tissue northern blots (Clontech) containing two $\mu \mathrm{g}$ of poly $(\mathrm{A})^{+}$mRNA isolated from a variety of human tissues were probed with a 5' or 3' probe specific for human erbin gene. Northern hybridization was performed according to the manufacturer's instructions. The blot was also probed with radiolabelled $\beta$-actin cDNA as an indicator of RNA loading.

\section{Immunolocalization and cell-surface labelling.}

For immunostaining procedures, MDCK cells grown on coverslips for three days after confluency were double labelled as described before ${ }^{50}$ with a monoclonal antibody against EGFR (LA22) and a rabbit polyclonal anti-gp1 14 antibody (an apical marker of MDCK cells) ${ }^{33}$. Caco-2 cells were grown on coverslips for at least 10 days after confluency to ensure full differenciation and then processed as MDCK cells. The antibody against Ag525 (a basolateral marker of human intestinal cells) was described before ${ }^{32}$. 
Frozen sections $(0.5-1.0 \mu \mathrm{m})$ of human colon were obtained as described ${ }^{32}$.

For cell-surface biotinylation, cells grown on filters for three days after confluency were labelled overnight with ${ }^{35}$ S-Promix Ready Vue from Amersham $\left(18.5 \mathrm{MBq} \mathrm{ml}^{-1}\right)$ on the basolateral side. Cells were labelled with Sulfo-NHS-LC-biotin (Pierce) after a 90 min chase in normal medium either on the apical or the basolateral side, and EGFR or chimeras were immunoprecipitated and streptavidin precipitated as described ${ }^{50}$. Samples were analysed by SDS-PAGE and visualized by fluorography. Autoradiograms were quantitated using Intelligent Quantifier from BioImage.

RECEIVED 2 FEBRUARY 2000; REVISED 10 APRIL 2000; ACCEPTED 10 APRIL 2000; PUBLISHED 8 JUNE 2000.

1. Ullrich, A. \& Schlessinger, J. Signal transduction by receptors with tyrosine kinase activity. Cell 61, 203-212 (1990).

2. Pawson, T. \& Scott, J. D. Signaling through scaffold, anchoring, and adaptor proteins. Science $\mathbf{2 7 8}$ 2075-2080 (1997).

3. Sternberg, P. W. \& Alberola-Ila, J. Conspiracy theory: RAS and RAF do not act alone. Cell 95, 447450 (1998).

4. Sieburth, D. S., Sun, Q. \& Han, M. SUR-8, a conserved Ras-binding protein with leucine-rich repeats, positively regulates Ras-mediated signaling in C. elegans. Cell 94, 119-130 (1998).

5. Hoskins, R., Hajnal, A. F., Harp, S. A. \& Kim, S. K. The C. elegans vulval induction gene lin-2 encodes a member of the MAGUK family of cell junction proteins. Development 122, 97-111 (1996).

6. Simske, J. S., Kaech, S. M., Harp, S. A. \& Kim, S. K. LET-23 receptor localization by the cell junction protein LIN-7 during C. elegans vulval induction. Cell 85, 195-204 (1996).

7. Kaech, S. M., Whitfield, C. W. \& Kim, S. K. The LIN-2/LIN-7/LIN-10 complex mediates basolateral membrane localization of the C. elegans EGF receptor LET-23 in vulval epithelial cells. Cell 94, 761771 (1998).

8. Whitfield, C. W., Benard, C., Barnes, T., Hekimi, S., \& Kim, S. K. Basolateral localization of the Caenorhabditis elegans Epidermal Growth Factor Receptor in epithelial cells by the PDZ Protein LIN 10. Mol. Biol. Cell. 10, 2087-2100 (1999).

9. Rongo, C., Whitfield, C. W., Rodal, A., Kim, S. K., \& Kaplan, J. M. LIN-10 is a shared component of the polarized protein localization pathways in neurons and epithelia. Cell 94, 751-759 (1998).

10. Songyang, Z. et al. Recognition of unique carboxyl-terminal motifs by distinct PDZ domains. Science 275, 73-77 (1997).

11. Fanning, A.S. \& Anderson, J. M. PDZ domains and the formation of protein networks at the plasm membrane. Curr. Top. Microbiol. Immunol. 228, 209-233 (1998).

12. Brenman, J. E. et al. Interaction of nitric oxide synthase with the postsynaptic density protein PSD 95 and alphal-syntrophin mediated by PDZ domains. Cell 84, 757-767 (1996).

13. Stricker, N.L. et al. PDZ domain of neuronal nitric oxide synthase recognizes novel C-terminal peptide sequences. Nature Biotechnol 15, 336-342 (1997).

14. Hillier, B. J., Christopherson, K. S., Prehoda, K. E., Bredt, D. S. \& Lim, W. A. Unexpected modes of PDZ domain scaffolding revealed by structure of nNOS-syntrophin complex. Science 284, 812-815 (1999)

15. Tochio, H., Zhang, Q., Mandal, P., Li, M. \& Zhang, M. Solution structure of the extended neuronal nitric oxide synthase PDZ domain complexed with an associated peptide. Nature Struct Biol 6, $417-$ 421 (1999).

16. Borg, J-P. et al. Identification of an evolutionarily conserved heterotrimeric protein complex involved in protein targeting. J.Biol.Chem. 273, 31633-31636 (1998)

17. Butz, S., Okamoto, M. \& Sudhof, T. C. A tripartite protein complex with the potential to couple synaptic vesicle exocytosis to cell adhesion in brain. Cell 94, 773-782 (1998).

18. Cohen, A. R., Wood, D. F., Marfatia, S. M., Walther, Z., Chishti, A. H., \& Anderson, J. M. Human CASK/LIN-2 binds syndecan- 2 and protein 4.1 and localizes to the basolateral membrane of epithelial cells. J. Cell. Biol. 142, 129-138 (1998).

19. Hsueh, Y. P., Yang, F. C., Kharazia, V., Naisbitt, S., Cohen, A. R., Weinberg, R. J., \& Sheng, M. Direct interaction of CASK/LIN-2 and syndecan heparan sulfate proteoglycan and their overlapping distribution in neuronal synapses. J. Cell. Biol. 142, 139-151 (1998).

20. Hata, Y., Butz, S. \& Sudhof, T. C. CASK: a novel dlg/PSD95 homolog with an N-terminal calmodulin-dependent protein kinase domain identified by interaction with neurexins. J. Neurosci. 16, 2488-2494 (1996).

21. Jo, K., Derin, R., Li, M. \& Bredt, D. S. Characterization of MALS/Velis-1, 2, and-3: a family of mammalian LIN-7 homologs enriched at brain synapses in association with the postsynaptic density95 /NMDA receptor postsynaptic complex. J. Neurosci. 19, 4189-4199 (1999).

22. Irie, M. et al. Isolation and characterization of mammalian homologues of Caenorhabditis elegans lin 7: localization at cell-cell junctions. Oncogene 18, 2811-2817 (1999).

23. Perego, C. et al. G. PDZ-mediated interactions retain the epithelial GABA transporter on the basolateral surface of polarized epithelial cells. EMBO J. 18, 2384-2393 (1999).

24. Borg, J-P., Ooi, J.Y., Levy, E. \& Margolis, B. The phosphotyrosine interaction domains of X11 and FE65 bind to distinct sites on the YENPTY motif of amyloid precursor protein. Mol. Cell. Biol. 16, 6229-6241 (1996).

25. Klapper, L. N., Kirschbaum, M. H., Sela, M. \& Yarden, Y. Biochemical and clinical implications of the ErbB/HER signaling network of growth factor receptors. Adv Cancer Res 77, 25-79 (2000).

26. Borg, J-P. \& Margolis, B. Function of PTB domains. Curr. Top. Microbiol. Immunol. 228, 23-38 (1998).

27. De Potter, C. R. et al. The subcellular localization of the neu protein in human normal and neoplastic cells. Int.J.Cancer 44, 969-974 (1989).

28. Apperson, M. L., Moon, I. S. \& Kennedy, M. B. Characterization of densin-180, a new brain-specific synaptic protein of the O-sialoglycoprotein family. J Neurosci. 16, 6839-52 (1996).

29. Bilder, D. \& Perrimon, N. Localization of apical epithelial determinants by the basolateral PDZ protein SCRIBBLE. Nature 403, 676-680 (2000).

30. Bateman, A. et al. The Pfam Protein Families Database. Nucleic Acids Res 28, 263-266 (2000).

31. Hock, B. et al. PDZ-domain-mediated interaction of the Eph-related receptor tyrosine kinase EphB3 and the ras-binding protein AF6 depends on the kinase activity of the receptor. Proc. Natl Acad. Sci. USA 95, 9779-9784 (1998).

32. Le Bivic, A., Bosc-Biern, I. \& Reggio, H. Characterization of a glycoprotein expressed on the basolateral membrane of human intestinal epithelial cells and cultured colonic cell lines. Eur. J. Cell Biol. 46, 113-120 (1988).

33. Le Bivic, A., Sambuy, Y., Mostov, K. \& Rodriguez-Boulan, E. Vectorial targeting of an endogenous apical membrane sialoglycoprotein and uvomorulin in MDCK cells. J. Cell. Biol. 110, 1533-1539 (1990).

34. Caplan, M. J. Membrane polarity in epithelial cells: protein sorting and establishment of polarized domains. Am. J. Physiol. 272, F425-F429 (1997).

35. Drubin, D. G. \& Nelson, W. J. Origins of cell polarity. Cell 84, 335-344 (1996).

36. Le Gall, A. H., Yeaman, C., Muesch, A. \& Rodriguez-Boulan, E. Epithelial cell polarity: new perspectives. Semin. Nephrol. 15, 272-284 (1995).

37. Cereijido, M., Valdes, J., Shoshani, L. \& Contreras, R. G. Role of tight junctions in establishing and maintaining cell polarity. Аnпu. Rev. Physiol. 60, 161-177 (1998).

38. Kornau, H. C., Seeburg, P. H. \& Kennedy, M. B. Interaction of ion channels and receptors with PDZ domain proteins. Curr. Opin. Neurobiol. 7, 368-373 (1997)

39. Irie, M. et al. Binding of neuroligins to PSD-95. Science 277, 1511-1515 (1997).

40. Wu, H., Reuver, S. M., Kuhlendahl, S., Chung, W. J. \& Garner, C. C. Subcellular targeting and cystoskeletal attachment of SAP97 to the epithelial lateral membrane. J. Cell Sci. 111, 2365-2376 (1998).

41. Straight, S. W. et al. mLin-7 is localized to the basolateral surface of epithelia via its $\mathrm{NH}(2)$ terminus. Am. J. Physiol. Renal. Physiol. 278, F464-F475 (2000).

42. Tsunoda, S. et al. A multivalent PDZ-domain protein assembles signalling complexes in a G-proteincoupled cascade. Nature 388, 243-249 (1997).

43. Chevesich, J., Kreuz, A. J. \& Montell, C. Requirement for the PDZ domain protein, INAD, for localization of the TRP store-operated channel to a signaling complex. Neuron 18, 95-105 (1997).

44. Woods, D. F. \& Bryant, P. J. The discs-large tumor suppressor gene of Drosophila encodes a guanylate kinase homolog localized at septate junctions. Cell 66, 451-64 (1991).

45. Bhat, M. A., Izaddoost, S., Lu, Y., Cho, K-O., Choi, K-W. \& Bellen, H. J. Discs Lost, a novel multiPDZ domain protein, establishes and maintains epithelial polarity. Cell 96, 833-845 (1999).

46. Kim, S. K. Polarized signaling: basolateral receptor localization in epithelial cells by PDZ-containing proteins. Curr. Opin. Cell Biol. 9, 853-859 (1997).

47. Hildebrand, J. D. \& Soriano, P. Shroom, a PDZ domain-containing actin-binding protein, is required for neural tube morphogenesis in mice. Cell 99, 485-497 (1999).

48. Levkowitz, G., Klapper, L. N., Tzahar, E., Freywald, A., Sela, M. \& Yarden, Y. Coupling of the c-CBL proto-oncogene product to ERBB-1/EGF-receptor but not to other ERBB proteins. Oncogene 12, $1117-1125$ (1996)

49. Fedi, P., Pierce, J. H., Di Fiore, P. P. \& Kraus, M. H. Efficient coupling with phosphatidylinositol 3kinase, but not phospholipase $\mathrm{C} \gamma$ or GTPase-activating protein, distinguishes ERBB-3 signaling from that of other ERBB/EGFR family members. Mol. Cell. Biol. 14, 492-500 (1994).

50. Le Bivic, A., Real, F. X. \& Rodriguez-Boulan, E. Vectorial targeting of apical and basolateral plasma membrane proteins in a human adenocarcinoma epithelial cell line. Proc. Natl Acad. Sci. USA 86, 9313-9317 (1989).

\section{ACKNOWLEDGMENTS}

We are grateful to M. Labouesse for sharing unpublished information. We thank G. Dressler for the mouse embryonic kidney cDNA library and the pc 86 and pc 97 vectors, G. Alcaraz for the rat brain cDNA library, M. Sheng for the constructs expressing the Myc-tagged PSD-95 and SAP97 proteins, Y. Kohara for the C.elegans ESTs (yk294 g5, yk524 b7, yk126 a10), W-Z. Wei for the pCMV-ERBB2 construct and J. Camonis for reagents enabling us to test the interaction between Ras and ERBIN. This project is supported by INSERM, ARC and Institut Paoli-Calmettes (V.O.). H.S. is a recipient of a Japanese-French fellowship. B.M. is an Investigator of the Howard Hughes Medical Institute.

Correspondence and requests for materials should be addressed to J-P.B. The accession numbers for the mouse and human ERBIN sequences deposited in GenBank are AF263743 and AF263744, respectively. 